\title{
PROJETO DE PESQUISA “REVISITANDO O PROJETO COLÚMBIA”
}

\author{
Lívia Diana Rocha Magalhães ${ }^{1}$ \\ José Claudinei Lombardi ${ }^{2}$ \\ Ana Palmira B. S. Casimiro ${ }^{3}$
}

\section{RESUMO}

No presente artigo retrata-se resultados da pesquisa ao Programa de Pesquisas Sociais Estado da Bahia Colúmbia University, doravante Projeto Colúmbia, como ficou conhecido o projeto articulado por Anísio Teixeira, então Secretário de Educação e Saúde do Estado da Bahia, em meados da década de 1940, tendo como coordenador o Dr. Thales de Azevedo. Esse projeto tinha como objetivo estudar as condições em que se encontravam a educação e a saúde em todo o Estado e foi desenvolvido em convênio com a Universidade de Colúmbia, nos Estados Unidos, perfazendo um ano de duração, segundo a linha de pesquisa mais avançada da antropologia de então. Essa pesquisa se dispôs a recuperar documentação e dados do Projeto Colúmbia, catalogar essa documentação por meio de uma leitura interdisciplinar dos materiais rastreados, investigar sua concepção, objetivos, metodologia, estado da arte, nível de avanço da pesquisa e o perfil de cada sujeito envolvido no projeto original, com o intuito de disponibilizar importantes fontes e análises sobre o papel da educação no desenvolvimento da Bahia e do Brasil em torno dos anos de 1950. Os objetivos centrais foram alcançados.

Palavras-Chave: Projeto Colúmbia; Estado da Arte; Relatório

\section{RESEARCH PROJECT "REVISITING THE COLUMBIA PROJECT"}

\begin{abstract}
In this article are demonstrated the search results to the "Program for Social Research of the State of Bahia Columbia University", called as Columbia Project, as it became known the project articulated by Anísio Teixeira, Secretary of Health and Education of the State of Bahia, in the mid-1940, having as coordinator Dr. Thales de Azevedo. The purpose of this project was to study the conditions in education and health throughout the state and has been developed in partnership with Columbia University, in the United States, that lasted one-year, according to the most advanced line of research in anthropology since then. This research set out to retrieve documents and data from Columbia Project and to catalog this documentation through an interdisciplinary reading perspective about the material screened to investigate their conceiving, objectives, methodology, state of the art, level of advancement of research and also the profile of each subject involved in the original project, in order to provide important sources and analysis about the role of education in the development of Bahia and Brazil around 1950's. The main objectives were achieved.
\end{abstract}

Keywords: Columbia Project. State of the art. Activities Report. 
No presente artigo retrata-se a pesquisa ao Programa de Pesquisas Sociais Estado da Bahia Colúmbia University, doravante Projeto Colúmbia, como ficou conhecido o projeto articulado por Anísio Teixeira, então Secretário de Educação e Saúde do Estado da Bahia, em meados da década de 1940, tendo como coordenador o Dr. Thales de Azevedo. Esse projeto tinha como objetivo estudar as condições em que se encontravam a educação e a saúde em todo o Estado e foi desenvolvido em convênio com a Universidade de Colúmbia, nos Estados Unidos. O Programa envolveu a vinda de três doutorandos da Universidade de Colúmbia, acompanhados de seu professor orientador Prof. Dr. Charles Wagley, para, com o auxílio de estudantes brasileiros, realizarem estudos de comunidade em três áreas diferentes do Estado, perfazendo um ano de duração, segundo a linha de pesquisa mais avançada da antropologia de então.

O Projeto Colúmbia foi garantido por recursos liberados pela Secretaria da Educação e Saúde do Governo da Bahia. Diante dessas informações, esta pesquisa se propõe a recuperar documentação e dados do Projeto Colúmbia, catalogar essa documentação por meio de uma leitura interdisciplinar dos materiais rastreados, investigar sua concepção, objetivos, metodologia, estado da arte, nível de avanço da pesquisa e o perfil de cada sujeito envolvido no projeto original, com o intuito de disponibilizar importantes fontes e análises sobre o papel da educação no desenvolvimento da Bahia e do Brasil em torno dos anos de 1950.

Para a revisita ao projeto Columbia pretendeu-se a) rever os temas históricos que alcançam a atualidade e nossas preocupações de estudos, por meio da recuperação das tramas de relações sincrônicas e diacrônicas do passado; b) revisitar a história, os documentos, os atores, o contexto da época, que envolveu a organização e realização do projeto, a partir de uma visão de longa duração; c) realizar a coleta, a catalogação e a musealização dos documentos, como um dos passos mais importantes para o registro, a análise e a sua compreensão teórica; d) rastrear e catalogar dados (manuscritos, relatórios, correspondências, falas e atos governamentais e de parlamentares, dissertações, teses, artigos de revistas e jornais, biografias, bibliografias, fotografias, mapas, filmes, depoimentos) que dizem respeito, direta ou indiretamente, ao projeto Programa de Pesquisas Sociais do Estado da Bahia Colúmbia University, aos seus personagens e/ou ao contexto do período pretendido, para recuperar as fontes mais importantes e reveladoras das ideias norteadoras do desenvolvimento cultural, principalmente da educação e da saúde na Bahia e no Brasil.

Por fim, o objetivo central desta revisita foi analisar de que modo projetos e programas que focaram o desenvolvimento social e a educação brasileira tiveram como referência básica o Projeto Colúmbia, articulado por Anísio Teixeira, em 1950, e como teriam pressionado os rumos tomados pelas relações sociais nas condições societais baianas durante o século XX. Isto, com a edificação de um aparato estatal devotado ao controle dos fluxos culturais e dos processos educacionais, na medida em que ambos atuam na delimitação de um quadro de valores cujo resultado é a invenção de um referencial identidário, calcado na consolidação de um hábito mental e um esquema gerador de práticas a Bahia como tradição e esta está na contrapartida da centralização do poder estatal regional na capital do Estado.

A partir destes objetivos, mais que o entendimento das correlações de força entre os grupos sociais em âmbito local naquele estágio, a expectativa é apreender o modo como, no rastro dos impulsos modernizadores em planos distintos, as redes sócio-humanas, no século XX, inauguram nacionalmente o acionar daquelas valorações e hegemonias com aguda penetração nos círculos de comando nacional e regional e, desde aí, decisivas ao 
aparecimento de institutos e órgãos comprometidos com a normatização do setor cultural, acoplando-o ao sentido de referencializar a singularidade da unidade baiana.

Aos pesquisadores do projeto coube localizar o Programa de Pesquisas Sociais Estado da Bahia Colúmbia University; por meio de sua história, seu contexto, sua relação com as políticas governamentais. Rastrear os arquivos e fontes documentais nas cidades em que projeto Columbia foi planejado ou desenvolvido. Identificar os sujeitos que estiveram direta ou indiretamente envolvidos no Projeto em estudo. Revisitar a literatura que deu origem ao Projeto, bem como a literatura resultante das suas pesquisas.

Caracterizar a natureza do Projeto em sua articulação com as diretrizes políticas estaduais, nacionais e internacionais e investigar os resultados do Projeto Columbia, suas conclusões, aplicação social, impacto, etc.

\section{Breve Fundamentação Teórica}

A literatura que se refere ao Programa de Pesquisas Sociais Estado da Bahia Colúmbia University é ampla e diversa e tem sido matéria de várias áreas de conhecimento: antropologia, história, educação, economia, sociologia, entre outras.

Conforme relata Consorte (2005) em meados de 1949, Dr. Anísio Teixeira, então Secretário de Educação e Saúde do Estado da Bahia convidou Dr. Thales de Azevedo para coordenar um projeto de pesquisa ambicioso, voltado para o estudo das condições em que se encontravam a educação e a saúde em todo o estado, e que seria desenvolvido em convênio com a Universidade de Colúmbia em Nova York. O Projeto Colúmbia, como ficou conhecido, envolveria a vinda, inicialmente, de três doutorandos da Universidade de Colúmbia, acompanhados de seu professor orientador para, com o auxilio de estudantes brasileiros, realizarem estudos de comunidade em três áreas diferentes do estado da Bahia, de um ano de duração, talvez, segundo a linha de pesquisa mais avançada da antropologia de então.

O Projeto Colúmbia foi integrado por um corpo de três diretores: pelo professor Thales de Azevedo (da Universidade da Bahia), pelo professor Charles Wagley (da Universidade de Colúmbia) e pelo professor Costa Pinto (da Universidade do Brasil), um jovem e já eminente sociólogo, que acompanharia o desenvolvimento do projeto em todas as suas fases (CONSORTE, 2005, p. 56). O Projeto foi garantido por recursos liberados pela Secretaria da Educação e Saúde do Governo da Bahia, e foi projetado um estudo preliminar sobre o Recôncavo Açucareiro, a Chapada Diamantina e o Sertão. Em cada uma delas foi escolhida uma comunidade representativa do Brasil arcaico ou tradicional, aquele que era considerado em via de desaparecimento e outra, representativa do Brasil moderno, aquele que vinha surgindo a partir do desenvolvimento ensejado pelo fim da segunda guerra mundial e que serviria como contraponto à primeira (CONSORTE, 2005, p. 57).

A metodologia do projeto privilegiou principalmente os chamados "estudos de comunidade" que de modo geral "refletem o ponto-de-vista do etnólogo em seus estudos de grupos primitivos, aplicado a segmentos locais de culturas modernas e complexas". (WAGLEY, C, 1955, p.1). Segundo Wagley e Azevedo (1990), o programa foi concebido tanto para "candidatos ao doutoramento na Columbia University e como plano básico para fornecer ao Estado estudos de uma serie de comunidades representativas para fins de planejamento educacional e de campanhas sanitárias" (p. 228).

Os estudos de Brandão (s/d), que recupera, sobretudo, os estudos sobre o Programa de Pesquisas Sociais no Estado da Bahia Colúmbia University e do departamento de 
ciências Sociais da UNESCO, serviram de importante referencial teórico inicial para o desenvolvimento da pesquisa, bem como as seguintes publicações: Race and Class in rural Brasil (Paris, UNESCO, 1952), organizado por Charles Wagley com artigos de Marvin Harris, W.H. Hutchinson e Bem Zimmerman; Les Élites de couleur dans une ville brésilienne (Paris, UNESCO, 1953, reeditado em português pela Editora Nacional, Rio de Janeiro, 1955, Série Brasiliana) de Thales de Azevedo, além de outros, também o próprio prefácio de Thales de Azevedo, sobre A Revolução Brasileira: uma análise da mudança social desde 1939, (Salvador: Livraria Progresso e Fundação para o Desenvolvimento da Ciência da Bahia (s/d)), no livro de Charles Wagley; assim como também, entre outras, as obras: Town and Country in Brasil de Marvin Harris, Village and Plantation Life in Northeastern Brasil de Harry W. Hutchinson, uma pesquisa sobre a vida social no Estado da Bahia de Wagley, Azevedo e Costa Pinto, e os artigos sobre métodos de campo no estudo da comunidade de Wagley e Azevedo, Povoamento das Lavras Diamantinas de Josildeth Consorte, Notas preliminares ao estudo da família no Brasil de Carmelita Junqueira Ayres Hutchinson, Estrutura de uma Comunidade do Nordeste Açucareiro e Comunidades e Fazendas de H.W. Hutchinson; inéditos estão, ainda, Princesa do Sertão: Uma História de Feira de Santana de Rollie E. Popino, Economic cycles in Brazil: the persistence of a total culture-pattern de Anthony Leeds e Um candomblé de caboclo da ilha de Itaparica de Carlos Costaldi (THALES (s/d) In: WAGLEY, Prefácio), que se tornaram referenciais obrigatórios para o estudo realizado.

\section{Metodologia}

Ainda são recentes os estudos sobre a educação brasileira que retratam as múltiplas histórias de homens e mulheres reais, vivendo a prática cotidiana, as filigranas do passado, a história social em suas diversas abordagens. Partindo da premissa de que a revisita a esse projeto proporcionaria uma compreensão simultânea das descontinuidades de cada tempo e das permanências e sobrevivência em sua construção de relações, interações complexas no tempo e no espaço (MAGALHÃES, 1999), passamos a considerar que do ponto de vista metodológico seria inevitável tratá-las a partir do triângulo espaço, tempo, ação, onde agentes, processos e racionalidades educativas se cruzam em sentindo sincrônico e diacrônico, sublinhando o quanto vem se tornando inevitável o alargamento objetual e da abordagem historiográfica, bem como o conceito de fonte historiográfica, uma vez que tudo gira em torno de um objeto comum a educação.

Também, operamos com a hipótese de que a constituição de um quadro institucionalizado de valores, a que chamamos de Bahia como tradição, poderia ser entendido como uma configuração-padrão, síntese, não apenas compreensível e explicada ao se levar em conta as situações e estruturas sociais particulares nas quais estão posicionadas classes e grupos num curso de um desenvolvimento social, mas também em sua dialética com a totalidade que dialoga. Com a finalidade de demonstrar nossa especulação teórica, mas de acordo com as limitações da natureza histórica e sociológica do objeto.

A pesquisa de caráter histórico-documental considerou as muitas versões sobre o significado e possibilidades de fontes: oral, escrita, cartográfica, iconográfica, entre outras. Priorizou-se o mapeamento e organização das fontes documentais e, para isso, recorreu-se aos arquivos de instituições como bibliotecas públicas e privadas e de órgãos públicos municipais em Salvador, Rio de Contas, Caetité, Rio de Janeiro, entre outras; também, depoimentos por meio da realização de entrevistas não dirigidas a pessoas que, em algum 
momento, ocuparam cargos ou tiveram outro tipo de participação no desenvolvimento do projeto revisitado; de igual modo, foram realizadas pesquisa bibliográfica e análise de teses, livros e documentos impressos, buscados em acervos particulares e via Internet. Também, foram realizadas entrevistas gravadas e filmadas, com participantes ou envolvidos direta ou indiretamente no Projeto e sobre as cidades de Monte Santo, Uruçuca, Rio de Contas e São Francisco do Conde.

Do ponto de vista dos procedimentos: primeiro foi realizado um plano de rastreamento e organização dos documentos. O levantamento preliminar indicou a existência de importantes fontes documentais, em Salvador, Rio de Contas, Caetité, em arquivos públicos e privados, bem como de referências fundamentais de articulação projeto no Rio de Janeiro. À medida que a equipe foi discutindo e realizando a leitura das fontes rastreadas à luz de referencias teóricas, começaram a ocorrer novas demandas e a busca de novas fontes.

Depois, cada pesquisador elegeu seu recorte de pesquisa a partir de temáticas mais amplas, como: a) O Projeto Columbia e sua relação com a cultura brasileira e a ideologia de caráter nacional no período em estudo. b) A ênfase do projeto sobre as questões étnicas com uma preocupação fundamental para a discussão sobre a "democracia racial" e sua articulação com a UNESCO (1951-1952). c) O panorama político e intelectual do período; d) Identificação de personalidades de referência no projeto; e) Implantação da Fundação para o Desenvolvimento da Ciência na Bahia; f) Organização das agências de pesquisa no Brasil; g) A articulação dos temas de estudo dos professores/pesquisadores com o tema geral do projeto. A leitura do material coletado visando ao conhecimento da história do Projeto Columbia e do contexto em que ocorreu a sua elaboração, ou seja, a leitura e análise de livros, artigos de periódicos, teses e documentos levantados permitiram a localização de novas fontes primárias e secundárias, e a participação de pesquisadores e bolsistas em reuniões de trabalho para a elaboração do primeiro plano de análise e organização de novos documentos.

Os pesquisadores realizaram a leitura do material coletado e em seguida as fontes passaram a ser analisadas à luz de recortes analíticos eleitos pelos pesquisadores nos seminários de trabalho. Foram realizados seminários de trabalhos a cada semestre e em um dos seminários de avaliação ocorreu a indicação de novos cotejamentos, análises de materiais e organização das produções para socialização dos resultados da pesquisa, conforme aditamento de prazo do projeto solicitado e aprovado pela Fundação de Amparo à Pesquisa do Estado da Bahia - FAPESB.

\section{Resultados}

A pesquisa possibilitou a recuperação de importantes documentos sobre o "Programa de Pesquisas Sociais do Estado da Bahia Columbia University", produções teóricas e um conjunto de informações que estavam dispersas e que com a pesquisa foram reunidas e passaram a compor um importante acervo. A realização da coleta, a catalogação e a musealização dos documentos se constituíram em um dos passos fundamentais para a análise e a compreensão teórica e o cotejamento de seu conteúdo com a finalidade e o objeto do programa revisitado em suas várias dimensões: social, política, econômica e, sobretudo, da sua importância para o entendimento da posição da Bahia perante o ideários de modernização estadual, nacional e internacional. Também permitiu a localização e catalogação de fontes bibliográficas que direta ou indiretamente servirão para o estudo da educação e da administração pública baiana entre os anos de 1940 e 1950. A pesquisa 
possibilitou a formação de uma rede de pesquisa ampla com outros pesquisadores e a articulação da equipe com colegas da UNICAMP, PUC, UNEB, UNB, entre outras, permitindo a organização de seminários, discussões e publicações conjuntas, além do fortalecimento do programa de pós-graduação em Memória: Linguagem e Sociedade (UESB) e o desenvolvimento de dissertações direta ou indiretamente relacionadas com o projeto, como também o envolvimento de alunos da iniciação científica (graduação) e dos cursos Lato Senso do MP em Educação, Cultura e Memória e Fundamentos Sociais e Políticos da Educação, por meio de bolsas de pesquisa e de elaboração de monografias. Todos os documentos foram praticamente digitalizados e compõem um CD-DVD (Guia de Fontes) que será disponibilizado publicamente, exceto livros em razões dos direitos legais de copyright.

A revisita ao projeto original, os seus atores e contexto da época, a partir de uma visão de longa duração, compôs, igualmente, um Vídeo-documentário produzido em parceria com a UNICAMP e PUC/SP, por meio do recurso do PROCAD/CAPES e da FAPESB (como parte da pesquisa material). A análise desses importantes documentos, sob recortes analíticos, possibilitou a edição de um livro, também em parceria com a equipe do PROCAD. A versão eletrônica do livro será disponibilizada nas páginas de todas as instituições/grupos envolvidas na pesquisa. Um documentário sobre o projeto e sobre as cidades, objetos de estudo do programa, foi produzido e será disponibilizado, inclusive com distribuição para TVs educativas. A pesquisa permitiu abrir mais uma página da História da Educação na Bahia e o entendimento da correlação de forças entre os grupos sociais, em âmbito local naquele período. De igual modo, possibilitou recuperar os impulsos modernizadores ordenados pelo intelectual e estadista baiano Anísio Teixeira, sob a direção de Thales de Azevedo, entre outros, e revelar os valores políticos e sociais hegemônicos nacional e internacionalmente naquele momento, assim como tentar entender os círculos de relações que se articularam em torno de idéias de mundo e de nação sob a direção da UNESCO e do comando nacional e regional da Bahia, decisivos ao aparecimento de institutos e órgãos comprometidos com o estudo científico da realidade, acoplando-o ao sentido de referenciar a singularidade a unidade baiana no campo da educação, da saúde, da economia, do seu desenvolvimento societário, por meio de seu redimensionamento cultural.

Como ressalta Medeiros (2011), a partir da análise dos documentos coletados durante a pesquisa, o Estado da Bahia também foi profundamente afetado com a crise mundial do capitalismo e com a política dos interventores do Estado Novo, agravando o seu processo econômico e social e aprofundando as altas taxas de mortalidade infantil, de analfabetismo, doenças, desemprego, surgimento de favelas, etc. O governo de Otávio Mangabeira (1947-1951) caracterizou este estado de coisas como o "enigma baiano". E o fato de a Bahia apresentar um quadro desfavorável ao processo de industrialização e consequentemente de modernização dentro do parâmetro nacional/internacional, recebeu atenção do próprio governo do Estado, entre outros setores. E, assim, o governo do Estado cria alternativas para examinar as causas desse fenômeno, cogitando entre outras medidas, a criação da Fundação para o Desenvolvimento das Ciências no Estado da Bahia, a partir da idealização proposta por seu secretário de educação Anísio Teixeira, que, por sua vez, propõe e celebra um convênio com a Universidade de Columbia para o conhecimento científico da realidade baiana, como um passo importante para o diagnóstico e a proposição de mudanças sistematizadas para o Estado.

$\mathrm{Na}$ revisita que realizamos a esse Programa, podemos observar que o método de estudos sobre comunidades preponderou, ao mesmo tempo em que se geraram importantes referenciais de análise sobre a Bahia e inclusive sobre o Brasil; por outra parte, também 
revelou um conjunto de mecanismos que integrou o projeto aos interesses da UNESCO quanto ao tema racial. Contudo, foram, sobretudo, as questões e indagações surgidas durante a pesquisa e a análise dos materiais coletados que possibilitaram uma visão de conjunto e ao mesmo tempo suas múltiplas particularidades e cruzamentos, alianças e negociações, mormente significativas, para o entendimento da Bahia e de sua circunscrição regional, mas também nacional e internacional, principalmente nos anos finais de 1940, por meio de sua inestimável capacidade de articulação científica e cultural no cenário nacional/internacional, efetivamente capitalizada pela intelectualidade de Anísio Teixeira e de seus colaboradores, entre eles Thales de Azevedo, o que não significou necessariamente um reflexo direto sobre a realidade pensada para ser modificada.

Dentre outros temas estudados durante a pesquisa, destacam-se as análises sobre: o contexto que gerou o Programa de Pesquisas Sociais no Estado da Bahia e a criação da Fundação para o Desenvolvimento das Ciências no Estado da Bahia (MEDEIROS, 20092011; SANTOS, 2009-2011); as relações de trabalho, pólos arcaicos e modernos, tratados a luz de análises "dualistas", segundo as quais o país apresenta uma dualidade de estruturas: um setor aberto moderno e outro fechado e arcaico (ALVES, 2009-2011); o contexto vivido e as produções do então coordenador do projeto professor e antropólogo Thales de Azevedo (SILVA b, 2009-2011); a tensão entre Igreja, Estado e os setores de Educação no contexto imediatamente anterior à implantação do Projeto Colúmbia na Bahia e suas possíveis mediações quando a Secretaria de Educação é assumida pelo professor Anísio Teixeira (CASIMIRO, 2009-2011); a recomposição da trajetória de pesquisa de Marvin Harris, em Rio de Contas e qual os impactos ou interferência desse estudo sobre os propósitos educativos ou administrativos do professor Anísio Teixeira (CONSORTE, AGUIAR, SANTANA, 2009-2011); as possíveis definições e rumos para a Política Educacional do Estado, a partir do Projeto Columbia, considerando não necessariamente sua materialização concreta, mas a memória dos valores, conduta teórica, política e epistemológica herdados desse período e sua possível transmissão política (MAGALHÃES, 2009-2011); como as informações anteriores ao projeto e articuladas por Anísio Teixeira quanto à concepção arquitetônica de escola, de certa forma inspirada na matriz norte-americana, também comparece nas suas expectativas previstas para a modernização baiana (SILVA a, 2009-2011); o papel das Ciências Sociais realizam uma revisão teórico-analítica sobre o papel das Ciências Sociais no "encaminhamento da questão a partir da implantação e institucionalização dos órgãos de cultura na Bahia, entre os anos de 1960 e 1980, para situar principalmente a relação entre o Projeto Columbia e uma política definida pelas mãos de uma intelligentsia nacional modernizadora (GUSMÃO, ANACIREMA, FARIAS, 2009-2011).

Deve-se acrescentar também que a análise sobre os estudos de comunidade que foram realizados naquele momento, em seus diferentes estágios de pesquisa de campo e suas publicações representaram um grande empreendimento, esforço intelectual e emprego de capital para o estudo sobre o problema da chamada mudança cultural e das relações funcionais e dos diversos elementos que compuseram o plano de pesquisa financiado pelo Governo do Estado da Bahia, visando o conhecimento empírico da cultura baiana e nacional brasileira, tendo em vista preocupações evidentes com a necessidade das transformações econômicas e social pelo qual a Bahia-Brasil estava passando, naquele dado período. Muitas lacunas sobre tais estudos foram respondidas; também, muitas outras se evidenciaram e agora estão compondo outros estudos derivados dessa pesquisa que se tornou inconclusa, diante das muitas possibilidades de análise apresentadas ao longo do seu desenvolvimento e pelos documentos coletados. 
Além das ações acima explicitadas, foram desenvolvidas duas monografias, uma intitulada "Raça e etnia em Thales de Azevedo: um estudo da obra "Elites de cor" numa cidade brasileira" e outra denominada "A educação em Vitória da Conquista - BA: o ideário modernizador e industrialista dos anos 1930 - 1950". Ambas as alunas foram bolsistas de pesquisa do projeto em pauta, sendo uma do PIBIC/CAPES e outra da FAPESB, respectivamente. Também houve a participação de mais três bolsistas de Iniciação Científica, sendo uma do PIBIC/CNPq que trabalhou com o recorte "Programa de Ciências Sociais no Estado da Bahia-Columbia University' como vetor para uma 'modernização conservadora' baiana", uma do PIC/UESB e outra da FAPESB que desenvolveram os recortes de pesquisa sobre "Projeto Columbia: uma revisita aos seus personagens vivos na Bahia" e "Projeto Colúmbia: Educação e Modernização na Bahia", respectivamente. Também ocorreu a defesa do projeto de pesquisa "A Região Cacaueira da Bahia no Columbia University: a contribuição de Anthony Leeds", do curso de especialização em Educação, Cultura e Memória do MP/UESB, e da dissertação "Memória do Trabalho e da Educação na produção do Espaço um estudo em Rio de Contas”, do mestrado em Memória: Linguagem e Sociedade (UESB). A pesquisa possibilitou ainda outros recortes de investigação, entre os quais: PROCAD N. 122/2007 Desenvolvimento Nacional e educação brasileira: Anísio Teixeira e o "Projeto Colúmbia"; Título do Projeto: Re-Visitando a Bahia: Diálogos entre Cultura, Educação e Política - Programa de Pós-Graduação em Memória: Linguagem e Sociedade - PPGMLS; "Revisitando o Programa Ciências Sociais no Estado da Bahia - Columbia university.

A síntese quantitativa dessas e outras ações pode ser vista no gráfico abaixo:

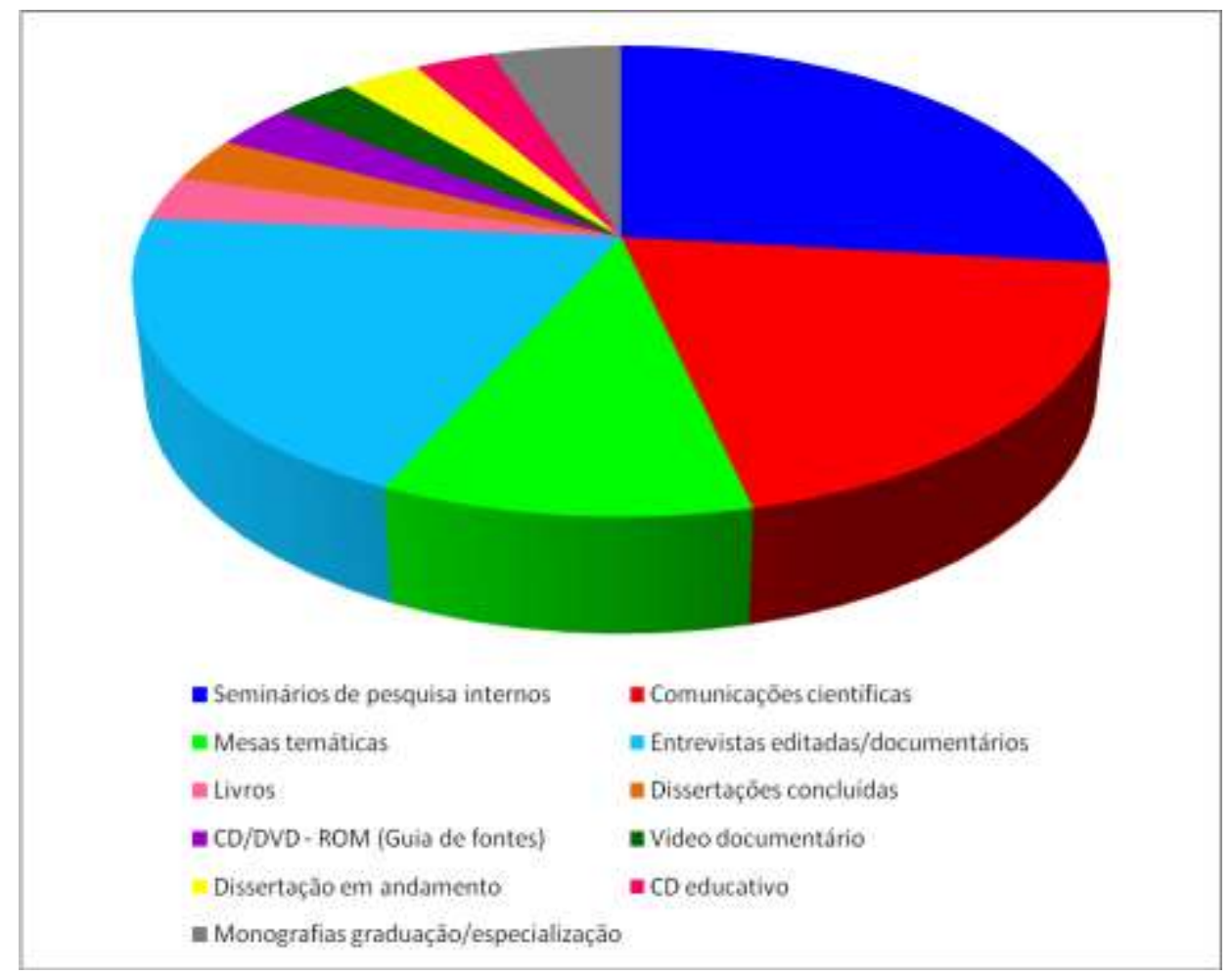




\section{Resultados Materiais}

Da pesquisa mencionada, resultou um vídeo-documentário em que os pesquisadores relatam o percurso da pesquisa e algumas conclusões, como a História do projeto Colúmbia, apresentam as cidades que foram objeto de estudo do Columbia, tanto na ocasião quanto agora (imagens e comentários) e informam sobre os principais resultados e importância da pesquisa para o entendimento do próprio Projeto Colúmbia, da Bahia, da História da Educação e para a repercussão do Projeto em várias áreas de conhecimento científico.

Resultou, ainda, um documentário composto de entrevistas com personagens envolvidos direta ou indiretamente no projeto que estudamos, com recurso do PROCAD em parceria com a equipe do projeto financiado pela FAPESB e UESB e constam de seis (06) entrevistas com: Profa. Josildeth Gomes Consorte e Profa. Maria Raimunda Guerra de Macedo Leôncio (Auxiliares de Pesquisa na ocasião do Programa em revisita); Prof. Luiz Henrique Tavares, Profa. Maria David de Azevedo Brandão, Prof. Ruy Hermann Araújo Medeiros, Prof. Demerval Saviani e Profa. Antonietta d'Aguiar Nunes (sobre o contexto do programa) e Frei Hugo Fragoso (sobre a relação entre Igreja e Estado naquele momento histórico).

Ademais, foram organizados e realizados seminários, livros, palestras, revistas científicas, comunicações em Congressos etc. contendo os textos produzidos pelos pesquisadores, conforme gráfico anterior.

\section{Conclusões}

De fato, a pesquisa aguçou o olhar dos pesquisadores para um conjunto de fontes e articulações políticas em torno da Bahia, de São Paulo, do Rio e Janeiro e até de fora do Brasil, protagonizadas, principalmente, pela UNESCO. Esta pesquisa está desencadeando muitas perguntas às evidências até então estudadas.

A maior parte das fontes coletadas foi digitalizada e esse material está no processo edição para ser disponibilizado aos pesquisadores envolvidos no Projeto, como também a todos os interessados através do site do Museu Pedagógico, por meio de um link específico o qual poderá ser acessado com senha própria. Além do site referido, haverá um CD-ROM com o acervo "Columbia university" e "Thales de Azevedo";

Ratificamos, enfim, que a revisita a história do projeto, os seus atores e contexto da época, a partir de uma visão de longa duração, comporá um Vídeo-documentário produzido em parceria com a UNICAMP e PUC/SP, por meio do recurso do PROCAD/CAPES e da FAPESB (como parte da pesquisa material). A análise desses importantes documentos será publicada em um livro (também em parceria com a equipe do PROCAD). A versão eletrônica do livro será disponibilizada nas páginas de todas as instituições/grupos envolvidas na pesquisa. Um documentário sobre o projeto e as cidades que foram objeto do programa será disponibilizado na página do Museu Pedagógico da UESB. 


\section{Referências}

ALVES, A.E.S. Memória do Trabalho Domiciliar e Gênero: apontamentos iniciais a partir da tese "Town and Country" de Marvin Harris", 2009-2011.

AZEVEDO, Thales de. Les élites de couleur dans une Ville Brésiliene. Paris: UNESCO, 1953.

BRANDÃO, Maria de Azevedo. (Org). Recôncavo da Bahia: Sociedade e Economia em Transição. Salvador: Fundação Casa de Jorge Amado; Academia de Letras da Bahia; Universidade Federal da Bahia.

CASIMIRO, A.P.B.S. Relação Igreja, Estado e Educação no Brasil: as relações com Columbia, 2009-2011.

CONSORTE, J Gomes. Itinerário de uma Pesquisadora: Sucessos e Percalços. In: MAGALHÃES, Lívia Diana Rocha e CASIMIRO, Ana Palmira Bittencourt Santos (Orgs.). Memória e Trajetória de Pesquisa. Campo Grande: Ed. UNIDERP, 2005 (p.5672).

HARRIS, M. Town and Country in Brazil: A socio-antropological study of a small Brazilian touw. Columbia University Press, New York, 1956.

HUTCHINSON, H.W. Village and Plantation Life in Northeastern Brazil. University of Washington Seattle: Press, 1957.

LEEDS, A. Economic Cycles in Brazil: the persistence of a culture pattern: cacao and other cases. University Microfilms, Ann Arbor, 1957.

LOMBARDI, J.C. Os Ecos da Cultura Política Brasileira: O Programa de Ciências Sociais no Estado da Bahia - Columbia University como vetor para uma modernização conservadora, 2009-2011.

MAGALHÃES, Justino P. Linhas de investigação em história da educação e da alfabetização em Portugal. Um domínio do conhecimento em renovação. In: LOMBARDI, José Claudinei (Org.). História da educação: perspectivas para o intercâmbio internacional. Campinas-SP: Autores Associados/HISTEDBR, 1999.

MAGALHÃES, L.D.R. As gerações do Projeto Columbia: memória escrita, 2009-2011.

MEDEIROS, R. O Programa de Pesquisas Sociais Estado da Bahia - Universidade de Colúmbia: o seu contexto, 2009-2011.

SANTOS, J.D. A sociogênese de um objeto cultural: saber e poder na formação da tradição popular afro-baiana, 2009-2011.

SILVA, A.C.G. O espaço escolar e o projeto Columbia: uma leitura preliminar, 20092011.

WAGLEY, C. "Brazilian Community Studies: Methodological evaluation". In: Anais do XXXI Congresso Internacional de Americanistas. São Paulo, 1955.

WAGLEY, C. (editor). Race and Class in Rural Brazil. UNESCO, Paris, 1952.

WAGLEY, C. A Revolução Brasileira: Uma análise da mudança social desde 1930. Tradução de Archimedes P.Guimarães. Salvador: Fundação para o Desenvolvimento da Ciência na Bahia; Livraria Progresso. 
WAGLEY, C. AZEVEDO, Thales de.; COSTA PINTO, Luiz de Aguiar. Uma pesquisa sobre a vida social no Estado da Bahia. Publicações do Museu do Estado $\mathrm{n}^{\circ} 11$, Secretaria de Educação e Saúde Bahia, Brasil, 1950.

WAGLEY, C. Estudos de comunidades no Brasil sob perspectiva nacional. Revista Brasileira dos Municípios; 1955. Ano VIII. N 31.

WAGLEY, C. AZEVEDO, Thales de. Sobre métodos de campo no Estudo de Comunidades. In: Revista do Museu Paulista, 1950.

Notas:

1 - Mestre em Educação pela Universidade de São Carlos - UFSCar; Doutora em Educação pela Universidade Estadual de Campinas - UNICAMP; com Pós-Doutorado em Psicologia Social pela Universidade Estadual do Rio de Janeiro - UERJ. Professora Plena do Departamento de Filosofia e Ciências Humanas - DFCH, da Universidade Estadual do Sudoeste da Bahia - UESB. Coordenadora Geral do Museu Pedagógico da UESB; Professora e Coordenadora do Programa de Pós-Graduação Stricto Sensu em Memória: Linguagem e Sociedade (UESB). Membro do HISTEDBR e do HISTED-BS. E-mail: lrochamagalhaes@gmail.com

2 Professor e pesquisador livre-docente do Departamento de Filosofia e História da Educação, da Faculdade de Educação da UNICAMP. Coordenador executivo do Grupo de Estudos e Pesquisas "História, Sociedade e Educação no Brasil" - HISTEDBR. Pesquisador do CNPq. Secretário da Educação de Limeira, SP. Email: jcl_zezo@hotmail.com

3 Professora do Departamento de Filosofia e Ciências Humanas da Universidade Estadual do Sudoeste da Bahia - UESB. Doutora em Educação pela UFBA e Pós-Doutora em Educação pela UNICAMP. É pesquisadora vinculada ao Grupo de Estudos e Pesquisas História, Educação e Sociedade no Brasil HISTEDBR e ao Museu Pedagógico, no qual coordena o Grupo de PesquisaFundamentos em Memória, Religião, Imagem e Educação. É autora de publicações na área de História da Arte e História da Educação, com ênfase em barroco e Brasil Colonial. E-mail: apcasimiro@oi.com.br

Recebido em nov/2013

Aprovado em nov/2013 